\title{
Developing juvenile localized scleroderma (jLS) consensus treatment regimens for comparative effectiveness studies
}

\author{
Suzanne C Li ${ }^{5 *}$, Robert C Fuhlbrigge ${ }^{2}$, Fatma Dedeoglu', Polly J Ferguson ${ }^{9}$, Gloria C Higgins ${ }^{6}$, Sandy D Hong ${ }^{9}$, \\ Heidi Jacobe ${ }^{11}$, Andrew Lasky ${ }^{3}$, Ronald M Laxer ${ }^{8}$, Mimi C Morris ${ }^{7}$, Elena Pope ${ }^{8}$, C Egla Rabinovich ${ }^{4}$, \\ Kathryn S Torok ${ }^{10}$, CARRAnet Investigators ${ }^{12}$
}

From 2011 Pediatric Rheumatology Symposium sponsored by the American College of Rheumatology Miami, FL, USA. 2-5 June 2011

\section{Purpose}

LS can cause significant morbidity in the growing child, including joint contractures and facial and extremity hemiatrophy. Optimal therapy is not known, and few randomized clinical trials have been carried out. A prior survey of Childhood Arthritis and Rheumatology Research Alliance (CARRA) members identified methotrexate (MTX) and corticosteroids (CS) as the most commonly used medications to treat serious jLS. However, there was no consensus on dose, route of administration, or duration of treatment for these medications. Objective: To develop standardized consensus treatment regimens and disease assessments tools for jLS.

\section{Methods}

A core group of pediatric rheumatologists based in CARRA was formed to evaluate and develop standardized jLS regimens and assessments. Two dermatologists who study jLS and a lay person were also recruited. Members reviewed literature on current treatments and assessments, and through surveys and Delphi processes, developed criteria to define different levels of disease severity, generated consensus regimens for jLS treatment, and agreed upon clinical parameters to evaluate disease activity and damage. Preliminary regimens and assessments were discussed with the CARRA membership, and modified based on feedback.

5Hackensack University Medical Center, Hackensack, NJ, USA

Full list of author information is available at the end of the article

\section{Results}

We have developed criteria to define high, moderate, and low disease severity, and standardized clinical activity and damage assessments for jLS. An atlas of lesion images was generated to facilitate scoring the level of several parameters (erythema, hyperpigmentation, hypopigmentation, dermal atrophy, and subcutaneous tissue loss). See table 1.

Through use of the Delphi process, the jLS core group was able to generate consensus initial treatment regimens for MTX, MTX with oral CS, and MTX with intravenous CS, including a general tapering regimen for oral corticosteroids. Table 2.

\section{Conclusion}

There is a need for standardized jLS disease assessments and treatment regimens to be able to compare treatment efficacy. A CARRA subgroup has developed consensus assessments and treatment regimens for $\mathrm{jLS}$. The efficacy of these regimens will be evaluated in future comparative effectiveness studies.

\section{Disclosure}

Suzanne C. Li: Arthritis Foundation, 2, Friends of CARRA, 2, NIAMS-NIH, 2; Robert C. Fuhlbrigge: Arthritis Foundation, 2, Friends of CARRA, 2, NIAMSNIH, 2; Fatma Dedeoglu: None; Polly J. Ferguson: None; Gloria C. Higgins: None; Sandy D. Hong: None; Heidi Jacobe: None; Andrew Lasky: None; Ronald M. Laxer: None; Mimi C. Morris: None; Elena Pope: None; C. Egla Rabinovich: None; Kathryn S. Torok: None; for the CARRAnet Investigators: None. 
Table 1 Parameters are scored for each involved anatomic site

\begin{tabular}{|c|c|c|c|}
\hline \multicolumn{3}{|c|}{ Clinical Activity Parameters: } & Clinical Damage Parameters: \\
\hline \multicolumn{3}{|l|}{ Scoring levels } & Scoring levels \\
\hline \multicolumn{3}{|c|}{ Erthema: 0 to 3} & Dermal atrophy: None, shiny, visible vessel, cliff-drop \\
\hline \multicolumn{3}{|c|}{ Violaceous color: None, lilac ring, viol. Center } & Subcutaneous tissue atrophy: 0 to 3 \\
\hline \multicolumn{3}{|c|}{ Development in lesion size: Yes/no } & Hyperpigmentation: 0 to 3 \\
\hline \multicolumn{3}{|c|}{ Change in lesion size: Smaller, stable, larger } & Hypopigmentation: 0 to 3 \\
\hline \multirow{2}{*}{\multicolumn{3}{|c|}{$\begin{array}{l}\text { Skin induration: lesion edge: } 0 \text { to } 3 \\
\text { Lesion warmth: Yes/no }\end{array}$}} & Skin thickness: lesion center: 0 to 3 \\
\hline & & & \\
\hline \multicolumn{4}{|c|}{ Distinct margin: None, erythematous, hyperpigmented margin } \\
\hline \multicolumn{4}{|l|}{ Table 2} \\
\hline \multicolumn{4}{|c|}{ Regimen } \\
\hline & MTX alone & $\mathrm{MTX}+\mathrm{CS}$ & MTX + IV CS \\
\hline MTX weekly dose & $1 \mathrm{mg} / \mathrm{kg} \mathrm{SQ}(\mathrm{max} 25 \mathrm{mg})$ & 1 mg.kg SQ (max 25 mg) & 1 mg.kg SQ (max 25 mg) \\
\hline \multirow[t]{4}{*}{ Initial CS dose, duration } & None & 2 mg/kg/day (max 60 mg) divided bid & 30 mg/kg/dpse (max $1 \mathrm{gm})$ \\
\hline & & Duration: at least 2 weeks & Either: 3 consecutive daily doses per month \\
\hline & & & OR 1 dose per week \\
\hline & & & Duration: 3 months \\
\hline \multirow[t]{5}{*}{ CS taper targets } & None & Down to: & None \\
\hline & & $1 \mathrm{mg} / \mathrm{kg} / \mathrm{d}$ (max $30 \mathrm{mg}$ ) by end of $2 \mathrm{~m}$ & \\
\hline & & $0.5 \mathrm{mg} / \mathrm{kg} / \mathrm{d}$ ( $\max 15 \mathrm{mg}$ ) by end of $4 \mathrm{r}$ & \\
\hline & & $0.25 \mathrm{mg} / \mathrm{kg} / \mathrm{d}(\max 7.5 \mathrm{mg}$ ) by end of 6 & \\
\hline & & Off CS by end of 48 weeks & \\
\hline
\end{tabular}

Author details

${ }^{1}$ Boston Childrens Hospital, Boston, MA, USA. 'Brigham and Women's Hospital, Boston, MA, USA. ${ }^{3}$ Childrens Mercy Hospital, Kansas City, MO, USA.

${ }^{4}$ Duke University Medical Center, Durham, NC, USA. ${ }^{5}$ Hackensack University Medical Center, Hackensack, NJ, USA. ${ }^{6}$ Nationwide Childrens Hospital, Columbus, OH, USA. 'ivingston, NJ, USA. ${ }^{8}$ The Hospital for Sick Children, Toronto, ON, Canada. ${ }^{9} \mathrm{U}$ of lowa Children's Hosp, lowa City, IA, USA. ${ }^{10}$ Univ of Pittsburgh Med Ctr, Pittsburgh, PA, USA. ${ }^{11}$ UT Southwestern Medical Center, Dallas, TX, USA. ${ }^{12}$ Stanford, CA, USA.

Published: 13 July 2012

doi:10.1186/1546-0096-10-S1-A68

Cite this article as: Li et al:: Developing juvenile localized scleroderma

(jLS) consensus treatment regimens for comparative effectiveness

studies. Pediatric Rheumatology 2012 10(Suppl 1):A68.

\section{Submit your next manuscript to BioMed Central and take full advantage of:}

- Convenient online submission

- Thorough peer review

- No space constraints or color figure charges

- Immediate publication on acceptance

- Inclusion in PubMed, CAS, Scopus and Google Scholar

- Research which is freely available for redistribution

Submit your manuscript at www.biomedcentral.com/submit
C Biomed Central 